special susceptibility may result partly from environmental factors and partly from drug induced impairment of cellular immunity.' AIDS thus compounds the risk of acquiring tuberculosis, and in the United States most patients with AIDS and tuberculosis have been drug abusers. ${ }^{238}$

The clinical manifestations of tuberculosis in patients with AIDS are varied and often atypical. Fever, fatigue, and weight loss are features of both conditions and not specific to either. The lungs are less often affected than other parts of the body, and the disease may become widely disseminated. ${ }^{9}$ Tuberculous lymphadenopathy is common and cannot be distinguished clinically from the lymphadenopathy of AIDS or the AIDS related complex. Other common sites of infection are the blood, bone marrow, genitourinary tract, liver, and peritoneum; the central nervous system may be affected by tuberculomas, cerebral abscesses, or tuberculous meningitis. ${ }^{10}$

The radiological pattern of pulmonary tuberculosis in patients with AIDS is often atypical ${ }^{11}$ : hilar or mediastinal lymph node enlargement is common; the middle or lower lobes are often affected while the upper lobes are spared; and cavitation is rare. Diagnosis depends on bacteriological examination of the sputum, induced if necessary by inhaling nebulised saline. ${ }^{12}$ When the sputum smear shows no bacilli bronchoscopy should be done and specimens obtained for bacteriological examination by bronchoalveolar lavage and transbronchial biopsy. The tuberculin skin test has limited value in diagnosis. About $40 \%$ of cases show a positive response, ${ }^{+}$but the reaction is usually weak and often becomes negative within a few months. If the search for tubercle bacilli is negative the diagnosis of extrapulmonary tuberculosis depends on pathological examination of suitable biopsy specimens, especially of lymph nodes. Granuloma formation is, however, often scanty or absent, and the lesions are depleted in lymphocytes; these features are characteristic of "areactive" tuberculosis.

The limited published information on treating patients with tuberculosis and AIDS shows that standard regimens of antituberculosis drugs are satisfactory, ${ }^{28}$ and in most patients with pulmonary disease the bacilli disappear from sputum in one to three months. The optimum duration of treatment has not been determined, but short course chemotherapy is unlikely to be adequate; courses of at least nine months are usually given' and in some cases are followed by daily isoniazid to prevent relapse. Hypersensitivity reactions to drugs are common in AIDS $^{13}$; they are encountered in patients treated with co-trimoxazole for infection with Pneumocystis carinii, ${ }^{14}$ and similar reactions might be expected to antituberculosis drugs. In patients who are likely to be on concurrent treatment for other infections or complications of AIDS identifying the cause of a drug reaction may be difficult. Multiple treatment also presents the risk of adverse interaction between drugs, and in one reported case interaction between ketoconazole (given for candidiasis) and rifampicin led to low serum concentrations of rifampicin. ${ }^{15}$

Until recently tuberculous infection in AIDS was not regarded as common, but American reports show an increasing incidence of tuberculosis among patients with AIDS, especially those in urban areas such as New York and New Jersey, where drug abuse is common. As Britain is likely to follow this trend, ${ }^{16}$ assiduous screening for tuberculosis is essential, and perhaps high risk subjects should be given prophylaxis with daily isoniazid. ${ }^{17} \mathrm{~A}$ drug abuser infected with the human immunodeficiency virus and with a positive tuberculin skin test might qualify for chemo- prophylaxis, but its efficacy for this type of case has yet to be assessed.

K P GOLDMAN

Consultant Chest Physician,

West Hill Hospital,

Dartford,

Kent DA1 2HF

1 Pinching AJ. The acquired immune deficiency syndrome: with special reference to tuberculosis. Tubercle 1987;68:65-9.

2 Sunderam G, McDonald J, Maniatis T, Oleske J, Kapila R, Reichman LB. Tuberculosis as a manifestation of the acquired immune deficiency syndrome (AIDS). JAMA 1986;256:362-6. Handwerger S, Mildvan D, Senie R, McKinley FW. Tuberculosis and the acquired immunodeficiency syndrome at a New York City hospital: 1978-1985. Chest 1987;91:176-80.

4 Pitchenik AE, Cole C, Russell BW, Fischl MA, Spira TJ, Snider DE. Tuberculosis, atypical mycobacteriosis and the acquired immunodeficiency syndrome among Haitian and non-Haitian patients in south Florida. Ann Intern Med 1984;101:641-5.

Biggar RJ. The clinical features of HIV infection in Africa. Br Med f 1986;293:1453-4.

6 Reichman LB, Felton CP, Edsall JR. Drug dependence, a possible new risk factor for tuberculosis disease. Arch Intern Med 1979;139:337-9.

Brown SM, Stimmel B, Taub RN. Immunologic dysfunction in heroin addicts. Arch Intern Med 1974;134:1001-3.

8 Duncanson FP, Hewlett D Jr, Maayan S, et al. Mycobacterium tuberculosis infection in the acquired immunodeficiency syndrome. A review of 14 patients. Tubercle 1986;67:295-302.

9 Centers for Disease Control. Diagnosis and management of mycobacterial infection and disease in persons with human immunodeficiency virus infection. Ann Intern Med 1987;106:254-6.

10 Bishburg E, Suderam G, Reichman LB, Kapila R. Central nervous system tuberculosis with the acquired immunodeficiency syndrome and its related complex. Ann Intern Med 1986;105:210-3.

11 Pitchenik AE, Rubinson HA. The radiographic appearance of tuberculosis in patients with the acquired immune deficiency syndrome (AIDS) and pre-AIDS. Am Rev Respir Dis 1985;131: 393-6.

12 Luce JM. Sputum induction in the acquired immunodeficiency syndrome. Am Rev Respir Dis 1986;133:513-4

13 Gordin MF, Simon GL, Wofry CB, Mills J. Adverse reactions to trimethoprim-sulphamethoxazole in patients with the acquired immunodeficiency syndrome. Ann Intern Med 1984;100:495-9.

14 Doble N, Hykin P, Shaw R, Keal EE. Pulmonary mycobacterium tuberculosis in the acquired immunodeficiency syndrome. BrMed $\mathcal{F}$ 1985;291:849-50.

15 Robertson JR, Bucknall ABV, Welsby PD, et al. Epidemic of AIDS related virus (HTLV-111/ LAV) infection among intravenous drug users. BrMed $\mathcal{F}$ 1986;292:527-9.

16 Bailey WC, Byrd RB, Glassroth JC, et al. National consensus conference on tuberculosis: preventive treatment of tuberculosis. Chest 1985;87(suppl):128-32.

\section{Insights from radiation treatment for benign disease}

One way that we have of studying the effects of low level ionising radiation is to follow up patients treated with radiation for benign disease between the 1920s and 1950s. Thus epilation with $x$ rays for ringworm resulted in an excess of carcinoma of the skin and thyroid, ${ }^{1}$ and thyroid carcinoma was also an important complication of radiotherapy for benign enlarged thymus glands. ${ }^{2} \mathrm{~A}$ threefold increase in leukaemia mortality in England and Wales between 1930 and 1955 together with the early reports of leukaemia in those who had survived the atom bomb and in patients treated with radiotherapy for ankylosing spondylitis prompted the initial study by Court Brown and Doll of over 14000 patients given radiotherapy for ankylosing spondylitis between 1935 and 1954. ${ }^{3}$ They showed an increased risk of leukaemia and other cancers, and a new report from Doll and others now presents the long term follow up on 14106 of those patients who were given a single course of $x$ ray treatment. ${ }^{4}$

There was a threefold increase in mortality from leukaemia in those irradiated compared with the general population. Mortality from neoplasms other than leukaemia or colonic cancer was also $28 \%$ higher. Both increases were thought to be caused by the previous radiotherapy, whereas the $30 \%$ increase in deaths from colonic cancer and the $51 \%$ increase in deaths from non-neoplastic disease were thought to be related to the ankylosing spondylitis and its association with other secondary diseases such as ulcerative colitis. The relative risk for leukaemia was highest between 2.5 and 4.9 years after the treatment but was still almost double that 
of the general population 25 years later. Nearly half the cases were diagnosed as acute myeloid leukaemia, and chronic lymphatic leukaemia was uncommon. These findings broadly agree with observations on the incidence of leukaemia in the Japanese who survived the atom bomb. ${ }^{5}$

The proportional increase in radiation induced cancers, including those of the oesophagus, lung, bones, lymphomas, breast, and brain, reached a maximum of $71 \%$ between 10 and $12 \cdot 4$ years after radiation treatment and then declined. Beyond 25 years the risk remained raised only for oesophageal cancer. This study is the first to show an apparent limit to the time during which radiogenic cancers may appear. The continued excess in oesophageal cancer shows, however, that this is not true for all cancers. Data on a selected group of solid tumours from the life span study of survivors of the atom bomb suggested that the relative risk did not vary between 5 and 30 years. ${ }^{5}$ Similarly, data from the follow up of women treated with radiation for carcinoma of the cervix has shown an increasing relative risk of cancer with time. ${ }^{6}$ Importantly therefore these data start to suggest the possibility of different time patterns of risk between different cancers.

The increased relative risk of breast cancer in the patients with spondylitis who received estimated doses of $0.5 \mathrm{~Gy}$ is in sharp contrast to the lack of increase in women who survived the atom bomb and who received comparable doses of radiation $(0 \cdot 1-1 \mathrm{~Gy}) .^{7}$ The results are, however, compatible with the increase among women given $x$ rays for acute postpartum mastitis in the 1940 s and $1950 \mathrm{~s}^{8}$; there was a threefold increase over the incidence in the unirradiated breast and a linear dose response relation of a $0.4 \%$ increase in risk for each rad between 60 and $500 \mathrm{rad}(0.6$ and 5.0 Gy). No dose response relations have been presented for the patients with spondylitis, and further analysis of possible dose relations will be important in understanding any heterogeneity of response.

The risks are, however, small. A member of the public receives four fifths of his total radiation exposure from the natural background sources and only one fifth from diagnostic and therapeutic procedures. ${ }^{9}$ Even so, occupational and general environmental radiation doses and doses from medical usage must be kept as low as possible. Therapeutic uses of radiation for benign disease must always be questioned, but alternative treatments-for example, phenylbutazone for ankylosing spondylitis-may also be leukaemogenic. ${ }^{10}$

Cancer Research Campaign Professor of

\section{NORMAN M BLEEHEN}

Clinical Oncology and Honorary Director

MRC Clinical Oncology and Radiotherapeutics Unit,

Addenbrooke's Hospital,

Cambridge CB2 2QQ

1 Ron E, Modan B. Benign and malignant thyroid neoplasms after childhood irradiation for tinea capitis. FNCI 1980;65:7-11.

2 Hempelmann LH, Hall WJ, Phill is M, Cooper RA, Ames WR. Neoplasms in persons treated with X-rays in infancy: fourth survey in 20 years. $7 N C I$ 1975;55:519-30.

3 Brown WMC, Doll R. Leukaemia and aplastic anaemia in patients treated for ankylosing spondylitis. London: HMSO, 1957.

4 Darby SC, Doll R, Gill SK, Smith PG. Long term mortality after a single treatment course with $\mathrm{X}$-rays in patients treated for ankylosing spondylitis. Brf Cancer 1987;55:179-90.

5 Darby SC, Nakashima E, Kato H. A parallel analysis of cancer mortality among atomic bomb survivors and patients with ankylosing spondylitis given X-ray therapy. $\mathcal{f}$ NCI 1985;75:1-21.

6 Boice JD, Day NE, Anderson A, et al. Second cancers following radiation treatment for cervical cancers following radiation treatment for cervical cancer. An international collaboration among cancer registries. $\mathcal{F} N C I$ 1985; 74:955-75.

7 Tokunaga $M$, Land CE, Yamamoto T, et al. Incidence of female breast cancer among atomic bomb survivors, Hiroshima and Nagasaki, 1950-1980. Hiroshima: Radiation Effects Research Foundation, Hiroshima. 1984. (Technical Report RERF TR15-84.)

8 Shore RE, Hildreth N, Woodard E, Dvoretsky P, Hempelmann L, Pasternack B. Breast cancer among women given X-ray therapy for acute postpartum mastitis. $3 N C I$ 1986;77:689-96.

9 International Atomic Energy Agency. Facts about low level radiation. Vienna: International Atomic Energy Agency, 1986. (Leaflet IAEA/PI/A 14E 85-06482.)

10 International Agency for Research on Cancer. Some miscellaneous pharmaceutical substances. London: International Agency for Reseach on Cancer, 1977. (Monograph 13.)

\section{Old and new causes of superficial dyspareunia}

Introital pain during intercourse or when inserting tampons occurs in up to $40 \%$ of women attending gynaecology clinics but is the principal symptom in few. ${ }^{1}$ Dyspareunia is both a cause and a symptom of sexual difficulty and is perhaps best investigated by a general practitioner or family planning doctor, although an increasing number of women are attending genitourinary medicine clinics as their first choice.

Managing superficial dyspareunia of acute onset is straightforward. It follows infection, allergy, or trauma - episiotomy or other injury from childbirth ${ }^{2}$ or gynaecological surgery. ${ }^{3}$ Postherpetic neuralgia can give pain without objective signs, and a common cause of superficial dyspareunia, which is not apparent on examination, is inadequate genital lubrication. ${ }^{4}$ This usually results from lack of effective sexual stimulation or from sociopsychological factors that inhibit arousal. If arousal fails during thrusting pain appears for the first time during intercourse rather than at penetration. Local trauma is a more likely cause of dyspareunia if the woman has atrophic genital epithelium after the menopause or another cause of oestrogen deficiency.

Chronic introital pain is more difficult to manage. It can follow acute infections or other problems-for example, postradiation vaginitis can develop years after radiotherapybut many of those with chronic disease have psychological disorders; diagnosing a psychological cause demands, however, excluding organic disease and positively finding psychological disorder. Psychosexual counselling does not cure all women. ${ }^{5}$

The clinical examination of a woman with longstanding dyspareunia needs to be more detailed than for one whose problem has begun acutely. The doctor must examine that part of the vestibule around and above the hymenal ring that contains the crypts of the minor vestibular glands. This is achieved by rolling the hymenal ring towards the vaginal orifice with a moistened applicator. ${ }^{5}$ Some women with chronic introital pain may have focal vulvitis, a newly described lesion characterised by intensely tender areas of focal erythema that may be swollen or ulcerated on the endodermal mucosa of the vestibule. ${ }^{5}$ Three quarters of the lesions are located around the openings of the Bartholin ducts or between them posteriorly (usually between 4 and 8 o'clock). They can be seen with the naked eye, but using a colposcope makes identification easier. They are exquisitely tender to touch, but the mucosa adjacent to them is nontender and looks normal.

Histological examination has not confirmed the association between the lesions and the minor vestibular glands, and there is no specific pattern of inflammatory reaction. Focal vulvitis can be differentiated from vulvitis circumscripta plasmacellularis (Zoon's vulvitis), a rare cause of dyspareunia, ${ }^{7}$ by the absence of infiltration by many plasma cells. The aetiology of focal vulvitis is unknown. It does not respond to local treatment with antimicrobial drugs, corticosteroids, cryotherapy, or systemic antibiotics, but about half of the women have a spontaneous remission, though this may be after 12 years. ${ }^{5}$

Local anaesthetics may give sufficient relief for intercourse. Woodruff and Parmley have excised the hymenal ring and contiguous mucosa and submucosa of the vestibule, ${ }^{6}$ but Peckham et al believe surgical treatment should be considered 